\title{
Clinical Characteristics and Prognostic Factors in Pediatric Chronic Rhinosinusitis with Polyps
}

\author{
Myoung Su Choi ${ }^{1}$, No Sun Park ${ }^{1}$, Seung-Gu Park ${ }^{1}$, Ho Yun Lee ${ }^{1}$, \\ Dong Sik Chang ${ }^{1}$, Chin Saeng Cho ${ }^{1}$, Jae hyuk Jang ${ }^{2}$, Myung-Shin Lee ${ }^{2}$, \\ Seung Min $\mathrm{Yoo}^{2}$, Hyun Jin Son ${ }^{3}$ and Ah-Young Kim ${ }^{1}$ \\ ${ }^{1}$ Departments of Otolaryngology-Head and Neck Surgery, ${ }^{2}$ Microbiology and Immunology, ${ }^{3}$ Pathology, \\ Eulji University College of Medicine, Daejeon, Korea
}

\section{소아 만성 비용성 비부비동염의 임상양상 및 예후인자}

최명수 ${ }^{1} \cdot$ 박노선 $^{1} \cdot$ 박승구 $^{1} \cdot$ 이호윤 ${ }^{1} \cdot$ 장동식 $^{1} \cdot$ 조진생 $^{1} \cdot$ 장재혁 $^{2} \cdot$ 이명신 $^{2} \cdot$ 유승민 $^{2} \cdot$ 손현진 $^{3} \cdot$ 김아영 $^{1}$ 을지대학교 의과대학 이비인후과학교실, ${ }^{1}$ 미생물학교실, ${ }^{2}$ 병리학교실 ${ }^{3}$

Received June 10,2013

Revised August 26, 2013

Accepted August 26, 2013

Address for correspondence

Ah-Young Kim, MD

Department of Otolaryngology-Head and Neck Surgery, Eulji University

College of Medicine,

95 Dunsanseo-ro, Seo-gu,

Daejeon 302-799, Korea

Tel $+82-42-611-3129$

Fax $+82-42-611-3136$

E-mail kimayong@eulji.ac.kr
Background and Objectives Chronic rhinosinusitis with nasal polyps is an uncommon pathology in the pediatric population and a challenging problem to otolaryngologists. In this study, we aimed to assess the clinical characteristics and postoperative results of children who underwent sinus surgery due to nasal polyps.

Subjects and Method We retrospectively reviewed medical records of 45 pediatric patients who had sinus surgery from 2009 to 2012 . We studied the relationship between clinical parameters and postoperative results.

Results Forty-five patients (18 women and 27 men with an age range of 8 to 17 years) were treated surgically in our hospital. We found statistically significant correlation between the preoperative CT scores $(p=0.043)$, the nasal obstruction symptom scores $(p=0.032)$ and postoperative recurrence, but not between other parameters.

Conclusion In this study, prognostic factors affecting the postoperative outcome were preoperative CT score and nasal obstruction symptom score.

Korean J Otorhinolaryngol-Head Neck Surg 2013;56:632-6

Key Words Endoscopy $\cdot$ Nasal polyps $\cdot$ Pediatrics $\cdot$ Prognosis $\cdot$ Sinusitis.

\section{서 론}

소아의 만성 비부비동염은 약물치료로 호전을 보이는 경 우가 대부분이나, 비용을 동반하거나 약물치료에 반응하지 않는 재발성 비부비동염의 경우 약물치료와 더불어 내시경 하 비부비동 수술을 통한 수술적 치료도 고려되고 있다. 그 러나, 소아 비용성 비부비동염의 경우 해부학적으로 크기나 위 치 등 성인 부비동과의 차이 등으로 수술적 치료에도 어려움 이 많으며, 수술 후에도 잦은 상기도 감염 등으로 인한 비부 비동염의 재발이 흔하고 수술 후 성장에 대한 불안감 등으로
수술적 치료 여부를 결정함에 있어 성인의 경우와 달리 어려 움이 있다. 이러한 이유들로 소아 비용성 비부비동염으로 수 술을 하는 환자수가 성인처럼 많지 않으며, 수술 후 결과를 예측할 수 있는 인자에 대한 연구도 미미한 형편이다.

이에 저자들은 비용을 동반한 소아 만성 비부비동염 환자 의 임상양상 및 비용의 조직학적 특성, 내시경하 부비동 수술 후 치료 결과 등을 조사해서 소아 환자의 임상적 특징을 이 해하고, 수술 후 예후에 영향을 미치는 요인들을 분석하고자 하였다. 


\section{대상 및 방법}

\section{대 상}

2009년부터 2012년까지 본원에서 비용을 동반한 만성 비 부비동염으로 진단을 받고 부비동 내시경 수술을 시행 받은 17 세 이하 45 명의 환자를 대상으로 하였다. 대부분의 환자는 타 병원에서 약물치료에 호전이 없거나 비용이 관찰되어 수술 을 위해 의뢰되었다. 외래에서 시행한 비내시경 소견과 부비동 전산화단층촬영 $(\mathrm{CT})$ 소견을 종합하여 진단하였으며, 알레르 기 진균성 부비동염, 진균종, 상악동 후비공 용종, 점액낭종, 급성 화농성 부비동염 등은 본 연구에서 배제하였다.

대상환자들의 의무기록 및 부비동 CT 영상, 조직검사를 후향적으로 분석하였으며, 증상점수, 동반질환(천식, 중이염, 비중격만곡증, 알레르기 비염, 아데노이드 비대증), 외래 내시 경 검사 소견, 혈액 호산구 수치, 알레르기 유무, 부비동 CT의 Lund-Mackay 점수,") 아데노이드-비인두 비율(A/N ratio), 조 직학적 비용의 분류, 수술 후 재발여부에 대하여 조사하였다. 수술은 병변의 정도 및 부위에 따라 내시경하 비부비동 수술 을 시행하였으며, 아데노이드 비대증이 심한 경우 아데노이드 절제술도 같이 시행하였다. 수술 후 외래 내시경 검사 관찰 중 비용이 재발한 경우 나쁜 예후군으로 분류하였다(Table 1).

Table 1. Epidemiological characteristics of subjects and patients

\begin{tabular}{lc}
\hline \multicolumn{1}{c}{ Parameters } & Data \\
\hline Age (yrs) & $14.6 \pm 2.6$ \\
Gender M/F & $27 / 18$ \\
Allergic rhinitis & $9(20 \%)$ \\
Middle ear disease & $4(8.9 \%)$ \\
Deviated nasal septum & $26(57.8 \%)$ \\
Blood eosinophil (\%) & $2.06 \pm 1.57$ \\
Adenoid/Nasopharynx ratio & $0.48 \pm 0.13$ \\
Endoscopic polyp score & $4.58 \pm 2.04$ \\
Preoperative CT score & $13.6 \pm 5.1$ \\
Postoperative recurrence & $9(20 \%)$ \\
\hline
\end{tabular}

M: male, F: female, CT: computed tomography

\section{증상 점수}

증상 점수는 수술 전 콧물, 코막힘, 후비루, 수면장애 등의 4가지 증상을 0에서 10점까지 visual analogue score(VAS) score를 통하여 조사하였다.

\section{알레르기 검사}

알레르기 비염 진단을 위해 피부단자검사나 multiple allergosorbent test(MAST) 검사를 시행하였다.

\section{비중격 만곡증 및 아데노이드 비대증 여부}

비중격 만곡증 및 아데노이드 비대증은 부비동 CT에서 진단하였으며, 아데노이드 비대증의 경우 측면 영상에서 $\mathrm{A} / \mathrm{N}$ ratio가 0.7 이상일 경우 아데노이드 비대증으로 진단하였다.

\section{수술 전 외래 내시경 검사}

수술 전 외래 내시경 검사를 통해 비용의 정도를 Fig. 1과 같이 0 부터 4 까지 분류한 후 양측 비용의 정도를 합산하였 다. 내시경으로 비용이 전혀 관찰되지 않는 경우를 0 , 중비도 이내에 국한된 비강점막의 부종성 변화가 관찰될 경우를 1 , 중비도 이내에 국한된 다수의 비용이 관찰될 경우를 2, 비용이 중비도 뿐만 아니라 나비벌집오목(sphenoethmoidal recess) 까지 공간을 차지하면서 비강을 부분적으로 폐쇄시키는 경 우를 3, 비용이 비강 전체를 폐쇄시키는 경우를 4로 분류하 여 조사하였으며, 이를 통계학적으로 분석하였다(Fig. 1). ${ }^{2)}$

\section{수술 전 부비동 CT의 Lund-Mackay 점수}

수술 전 부비동 CT 결과는 Lund-Mackay 점수(0 24점)로 평가하였다.

\section{비용의 조직학적 분류}

수술 중 채취한 후 비용 조직을 조직병리학과 전문의에 의 해 호산구 부종형(eosinophilic edematous type), 만성 염증 성 섬유형(chronic inflammatory or fibrotic type), 장점액

Fig. 1. Polyp grading system via nasal endoscope. Polyp grading system: 0 , no visible polyp; 1 , small amount of polypoid disease confined within the middle meatus; 2 , multiple polyps occupying the middle meatus; 3 , polyps extending beyond the middle meatus, within the sphenoethmoid recess but not totally obstructing, or both; 4, polyps completely obstructing the nasal cavity. MT: middle turbinate, IT: inferior turbinate.

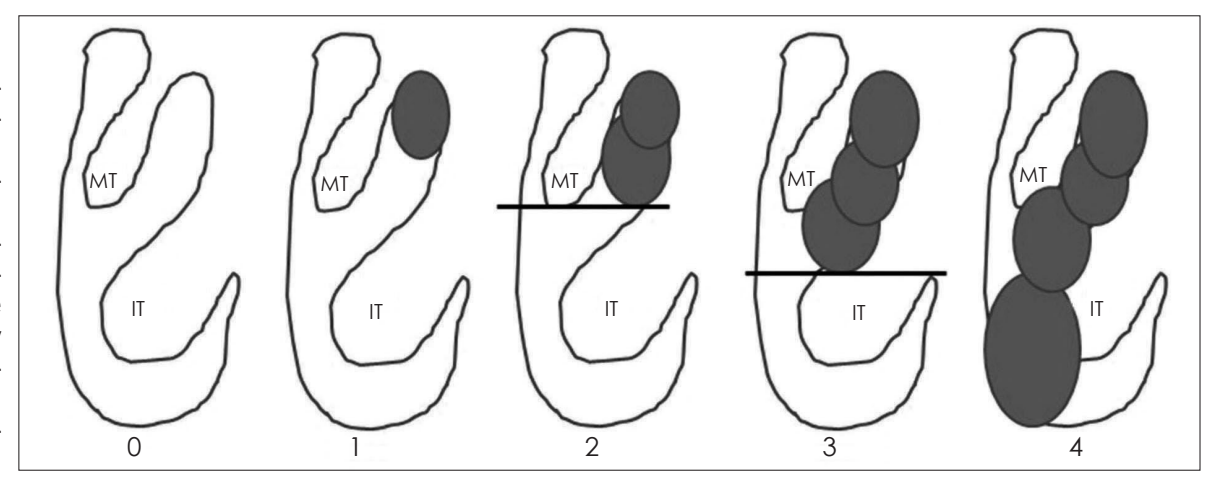


Table 2. Histological classification of nasal polyps

\begin{tabular}{lc}
\hline \multicolumn{1}{c}{ Type } & $\begin{array}{c}\text { Prevalence of } \\
\text { patients (\%) }\end{array}$ \\
\hline Eosinophilic edematous type & 47 \\
Chronic inflammatory or fibrotic type & 31 \\
Seromucinous gland type & 13 \\
Atypical stromal type & 9 \\
\hline
\end{tabular}

성 선형(seromucinous gland type), 그리고 비정형적 기질형 (atypical stromal type)의 4가지 유형으으로 분류하여 조사 하였다(Table 2). 점막 고유층의 심한 부종과 많은 수의 호산 구의 침윤이 관찰되었을 경우 호산구 부종형으로 분류하였 고, 간질조직내 섬유세포의 증식을 보이며, 많은 림프구와 호 중구의 침윤이 관찰되는 경우 만성 염증성 섬유형으로, 장점 액성 선조직이 다수 관찰되는 경우 장점액성 선형으로, 비정형 적으로 방추상의 기질이 관찰되는 경우를 비정형적 기질형으 로 분류하였다.

\section{통계학적 평가}

통계는 두 군 간의 연속형 숫자 변수 비교에는 Mann-Whitney U test, 세 군 이상의 연속형 숫자 변수 비교에는 KruskalWallis test를 사용하였고, 명목 변수 간의 관련성 확인에는 Fisher's exact test를 이용하여 $p<0.05$ 인 경우 통계적으로 유 의하다고 판정하였다. 예후인자 각각에 대한 통계방법을 좀 더 자세히 기술하면, 성별, 중이염 유무, 비중격 만곡증 유무, 알레르기 비염 유무, 아데노이드 비대증 유무 등은 Fisher's exact test를 통하여 수술 후 예후와의 관련성을 통계학적으 로 분석하였고, 나이 및 혈중 호산구 수치, VAS 증상점수, A/ $\mathrm{N}$ ratio, 수술 전 내시경검사에서 비용의 정도, 수술 전 LundMackay 점수 등은 Mann-Whitney U test를 통하여 수술 후 통계학적으로 분석하였다. 조직학적 분류와 수술 후 예후 와의 관련성은 Kruskal-Wallis test를 이용하여 통계학적으 로 분석하였다. 통계프로그램은 SPSS 12.0(SPSS Inc., Chicago, IL, USA)을 사용하였다.

\section{결 과}

\section{대상 및 임상증상과 수술 후 경과}

총 45 명의 환자 나이는 8 세부터 17 세까지 평균 $14.6 \pm 2.6$ 세였으며, 성비는 남자가 27명(60\%), 여자가 18명(40\%)이었 다. 그 중 9명(20\%)의 환자가 알레르기 비염을 동반하였으며, 4명(8.9\%)의 환아가 삼출성 중이염을, 26 명(57.8\%)의 환아가 비중격 만곡증을 동반하고 있었다. 나이 및 성별, 중이염, 비중 격 만곡증 여부는 예후와 통계학적 유의성이 관찰되지 않았
Table 3. Prognostic factors affecting postoperative recurrence

\begin{tabular}{lc}
\hline \multicolumn{1}{c}{ Factors } & p value \\
\hline Age (yrs) & 0.371 \\
Gender M/F & 0.647 \\
Allergic rhinitis & 0.653 \\
Middle ear disease & 0.882 \\
Deviated nasal septum & 0.355 \\
History of previous operation & 0.078 \\
Nasal symptoms & \\
$\quad$ Nasal obstruction & $0.032^{*}$ \\
$\quad$ Rhinorrhea & 0.085 \\
$\quad$ Postnasal drip & 1.000 \\
$\quad$ Sleep disturbance & 0.123 \\
Adenoid/Nasopharynx ratio & 0.932 \\
Endoscopic polyp score & 0.311 \\
Preoperative CT score & $0.043^{*}$ \\
Blood eosinophil (\%) & 0.172 \\
Biopsy result & 0.870 \\
\hline
\end{tabular}

*p<0.05. M: male, F: female, CT: computed tomography

다(Table 1 and 3).

임상 증상을 VAS 점수로 조사한 결과, 대부분의 환자에서 코막힘, 콧물, 후비루, 수면장애 4가지 증상을 모두 호소하였 으며, 코막힘 $7.64 \pm 1.81$, 콧물 $6.76 \pm 1.89$, 후비루 $6.62 \pm 1.762$, 수면장애 7.04 \pm 1.24 로 조사되었고, 각 증상 점수에 따른 예 후와의 관련성을 조사한 결과 코막힘의 경우 좋은 예후를 보 였던 환자군보다 나쁜 예후를 보인 환자군에서 유의하게 높 은 증상점수를 보였다 $(p=0.018)$. 콧물 및 후비루와 수면장애 의 경우 유사한 경향을 보였지만 통계학적으로 유의하지는 않았다(Fig. 2, Table 3).

수술 후 45명 중 9명(20\%)의 환자에서 외래 경과 관찰 중 수술 부위 비강 점막에 비용의 재발 양상이 관찰되었다. 이 중 3 명의 경우 약물치료 후 호전되었고, 4 명의 경우 비용이 재 발하여 재수술을 시행 받았으며, 2명의 경우 재수술을 원하 지 않아 약물치료 하였으나 호전은 관찰되지 않은 상태였다.

\section{혈중 호산구 수치 및 MAST 검사 결과}

혈중 호산구 수치는 $2.06 \pm 1.57 \%$ 였으며, 통계학적으로 예 후와의 관련성은 보이지 않았다. 피부반응검사 및 MAST 검 사에서 9 명(20\%)의 환자가 집먼지 진드기나 곰팡이, 잔디꽃 가루 등에 양성반응을 보였으며 통계학적으로 예후와의 관 련성은 없었다(Table 1 and 3).

\section{수술 전 내시경하 비용 정도 및 부비동 CT Lund-Mackay 점수, 아데노이드-비인두 비율 $(\mathrm{A} / \mathrm{N}$ ratio)}

수술 전 내시경 검사에서 비용의 정도를 분류한 결과 평균 
Fig. 2. VAS symptom score between good and poor prognostic group. Symptom scores of nasal obstruction are higher in poor prognostic group than in good prognostic group $(p=$ $0.018)$. VAS: visual analogue score.

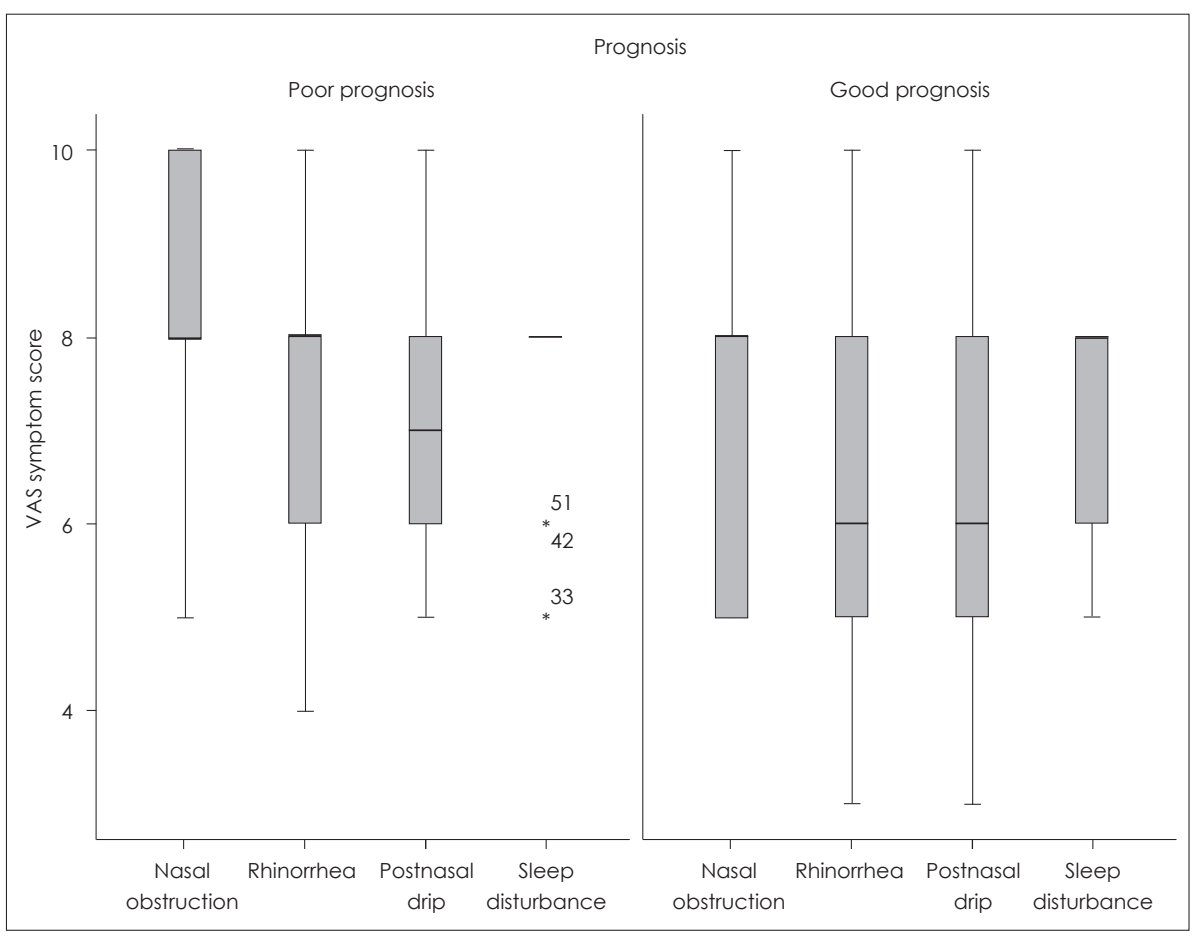

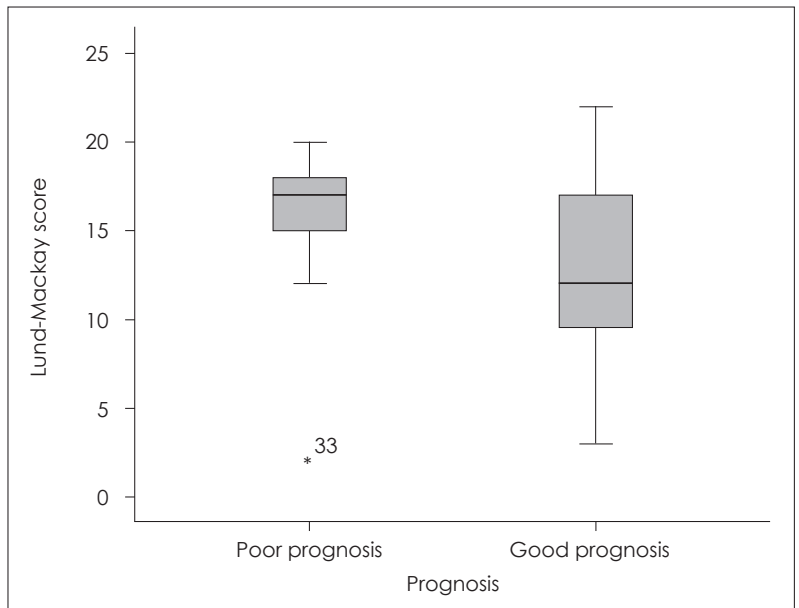

Fig. 3. Lund-Mackay CT score between good and poor prognostic group. Lund-Mackay CT scores are higher in poor prognostic group than in good prognostic group $(p=0.021)$. CT: computed tomography.

$4.58 \pm 2.04$ 였으며, 예후와의 관련성은 통계학적으로 유의하 지 않았다 $(p=0.311)$ (Table 1 and 3).

부비동 CT의 Lund-Mackay 점수는 2 24점까지 조사되 었으며, 평균 13.6 \pm 5.1점이었으며, 나쁜 예후를 보인 환자에 서 통계학적으로 유의하게 Lund-Mackay 점수가 높았다 ( $p=0.043$ )(Fig. 3, Table 3). A/N ratio는 $0.48 \pm 0.13$ 으로 측 정되었으며, 예후와의 관련성은 통계학적으로 유의하지 않았 다(Table 3).

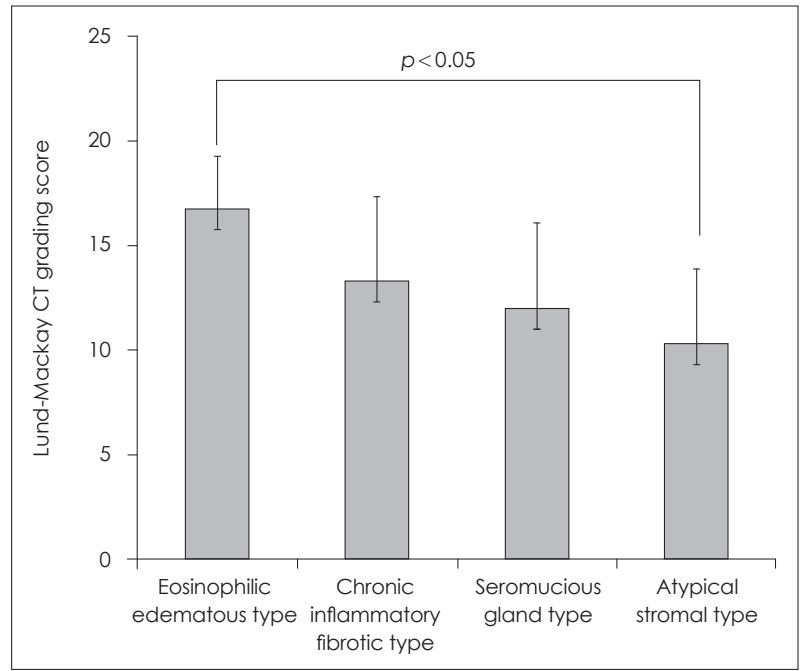

Fig. 4. Lund-Mackay CT score according to pathology type. LundMackay CT scores are higher in the eosinophilic edematous type than in the atypical stromal type $(p=0.009)$. CT: computed tomography.

\section{조직학적 비용 분류}

비용을 H\&E 염색 후 조직학적으로 분류한 결과 eosinophilic edematous type(47\%), chronic inflammatory type (31\%), seromucinous gland type(13\%), atypical stromal type(9\%)으로 조사되었다. 조직학적 분류의 경우 KruskalWallis 통계 분석 결과 비용 분류에 따른 Lund-Mackay CT score 점수에는 유의한 차이를 보였으며 $(p=0.009)$, eosinophilic edematous type은 atypical stromal type보다 유의하 
게 높은 CT score를 보였다 $(p=0.023)$ (Fig. 4). 조직검사 결과 에 따른 예후의 차이를 알아보기 위해 chi-square 분석을 시 행했으나 개체수가 적어 유의한 결론을 내리지 못했다.

\section{고 찰}

소아 비부비동염은 치료 후에도 증상이 남아있거나 재발이 흔한 등 그 양상이 성인의 비부비동염과는 다른 임상 양상과 예후를 보인다. 그러나 소아의 비부비동염에 대한 연구는 부 족하며, 특히 예후에 영향을 미치는 인자는 아직 잘 알려져 있 지 않고, 여러 문헌보고 ${ }^{4-13}$ 마다 논란의 여지가 있어 이에 대 한 지속적인 연구가 필요하다.

소아 만성 비부비동염의 수술적 치료 성공률은 55 93\% ${ }^{4-13)}$ 까지 문헌에 따라 다양하게 보고되고 있으며, 본 연구에서의 수술 성공률은 80\%로 타 문헌 보고와 차이가 없었다. 성공률 에 영향을 미치는 예후인자에 대해서도 보고자에 따라 다르 게 보고되고 있다. Song 등근 6세 미만의 나이, 간접흡연이 나쁜 예후 인자임을 보고하였으며, $\operatorname{Kim}$ 등은 수술 전 비용 의 정도와 수술 전 CT의 병변정도, 간접 흡연 등이 통계학적 으로 유의하게 예후와 관련이 있다고 보고하기도 하였다. Dhong 등은 수술 전 여러 인자들과 예후와의 관련성을 조 사하였으나 모두 통계학적 유의성이 없었다고 보고하기도 하 였다.

저자들은 다른 문헌보고에서 조사하였던 예후인자들(나 이, CT 병변정도, 내시경하 비용 정도, 아데노이드 비대증, 알 레르기 비염, 비중격 만곡증 유무, 증상점수, 혈중 호산구 수 치)뿐만 아니라 조직학적 비용의 분류에 따른 예후의 차이를 조사하였으며, 통계학적으로 유의한 차이를 보이는 나쁜 예후 인자는 수술 전 코막힘 증상과 Lund-Mackay score였다. 이 는 코막힘이 심하고 CT score가 높을수록 정상 비강 점막의 부위보다 병적인 점막의 범위가 더 넓고, 따라서 내시경적 수 술적 치료로 비용을 제거하고 비부비동의 환기를 호전시켜 준 후에도 재발 가능성이 높은 것이 아닌가 사료된다.

조직학적 분류의 경우 eosinophilic edematous type의 환 자가 높은 CT score를 보임이 관찰되었으나 예후와는 개체 수가 적어 통계적 처리가 어려웠으며, Lund-Mackay 점수와 의 관련성으로 유추하여 볼 때 조직학적 분류에 따른 예후 의 차이를 알아보기 위해 좀더 많은 환자를 대상으로 한 연 구가 필요할 것이다.

저자들의 경우 소아 비용에 대한 점액유전자 연구가 드물
며, 성인에 비하여 소아의 경우, 임상적으로 증상이 심하고, 콧 물과 코막힘 등의 증상도 성인에 비하여 심하게 호소하는 경 우가 많으며, 지속적인 치료에도 재발의 경우가 많아 성인의 점액유전자와의 차이점을 알아보기 위해 예비 연구로 발현 의 차이를 보고자 하였다. 그러나 실험 및 유전자 관련 검사 에 동의를 한 환자 수가 적어 통계학적 의미를 찾기는 어려웠 으며, 성인과 소아에서 점액분비 유전자 발현의 차이는 보이 지 않았다. 점액유전자에 대한 연구는 대상 소아 비용의 환자 수가 적고, 적절한 성인과 소아의 환자군 선정이 어려워 제한 점이 있으나, 소아 비부비동염에 대한 좀더 많은 이해 및 치 료를 위해서도 향후 좀더 많은 대상을 통한 연구가 필요할 것으로 생각된다.

\section{Acknowledgments}

This article is supported by an Eulji University Research Grant.

\section{REFERENCES}

1) Lund VJ, Mackay IS. Staging in rhinosinusitus. Rhinology 1993; 31(4):183-4.

2) Meltzer EO, Hamilos DL, Hadley JA, Lanza DC, Marple BF, Nicklas RA, et al. Rhinosinusitis: developing guidance for clinical trials. J Allergy Clin Immunol 2006;118(5 Suppl):S17-61.

3) Pawankar R. Nasal polyposis: an update: editorial review. Curr Opin Allergy Clin Immunol 2003;3(1):1-6.

4) Song HM, Yu MS, Park HW, Chung YS, Lee BJ, Jang YJ. Clinical characteristics and treatment outcomes of endoscopic sinus surgery in pediatric chronic rhinosinusitis. Korean J Otolaryngol-Head Neck Surg 2006;49(2):168-73.

5) Kim HY, Dhong HJ, Chung SK, Chung YJ, Min JY. Prognostic factors of pediatric endoscopic sinus surgery. Int J Pediatr Otorhinolaryngol 2005;69(11):1535-9.

6) Dhong HJ, Chung YJ, Ha BS. Prognostic factors of pediatric endoscopic sinus surgery. Korean J Otolaryngol-Head Neck Surg 2003;46(8):654-8.

7) Tsukidate T, Haruna S, Fukami S, Nakajima I, Konno W, Moriyama H. Long-term evaluation after endoscopic sinus surgery for chronic pediatric sinusitis with polyps. Auris Nasus Larynx 2012;39(6): 583-7.

8) El Sharkawy AA, Elmorsy SM, Eladl HM. Functional endoscopic sinus surgery in children: predictive factors of outcome. Eur Arch Otorhinolaryngol 2012;269(1):107-11.

9) Lee JY, Lee SW. Influence of age on the surgical outcome after endoscopic sinus surgery for chronic rhinosinusitis with nasal polyposis. Laryngoscope 2007;117(6):1084-9.

10) Lusk RP, Muntz HR. Endoscopic sinus surgery in children with chronic sinusitis: a pilot study. Laryngoscope 1990;100(6):654-8.

11) Rosenfeld RM. Pilot study of outcomes in pediatric rhinosinusitis. Arch Otolaryngol Head Neck Surg 1995;121(7):729-36.

12) Stankiewicz JA. Pediatric endoscopic nasal and sinus surgery. Otolaryngol Head Neck Surg 1995;113(3):204-10.

13) Bolt RJ, de Vries N, Middelweerd RJ. Endoscopic sinus surgery for nasal polyps in children: results. Rhinology 1995;33(3):148-51. 